\title{
The process of oligodimethylsiloxane with terminal hydroxyl groups and isopropyl ether of orthotitanic acid interaction
}

\author{
(C) Vladimir Yu. Chuklanov, ${ }^{1}{ }^{+}$Kirill V. Smirnov, ${ }^{1}$ and Natalia V. Chuklanova ${ }^{2}$ \\ ${ }^{1}$ Vladimir State University Named after A.G. and N.G. Stoletovs. Gorkogo St., 87. Vladimir, 600000. Russia. \\ Phone: +7 (4922) 479-619; (4922) 47-97-53. \\ ${ }^{2}$ Ivanovo State Polytechnic University. Sheremetevsky Ave., 21. Ivanovo, 153000. Ivanovo Region. Russia. \\ Phone:+7 (904)030-0861.E-mail:vladsilan@mail.ru
}

\begin{abstract}
*Supervising author; ${ }^{+}$Corresponding author
Keywords: polydimethylsiloxane, orthotitanic acid isopropyl ester, elastomer, adhesion, kinetics.
\end{abstract}

\begin{abstract}
The process of oligodimethylsiloxane with terminal hydroxyl groups and isopropyl ether of orthotitanic acid interaction was studied. This process leads to the formation of dimethylsiloxane elastomer, which is a valuable product in the production of sealing materials, high-temperature protective coatings, the starting product for heat-conducting pastes. The synthesis was carried out at a temperature of $25{ }^{\circ} \mathrm{C}$ due to the interaction of the terminal hydroxyl groups of the oligomer and the isopropoxy groups of the orthotitanic acid ester. The reaction was accompanied by the release of isopropyl alcohol, which was effectively removed from the reaction zone due to its high volatility. Along with the polycondensation reaction, an additional hydrolysis reaction of unreacted orthotitanic acid ether in the presence of atmospheric moisture is possible. The final product of the reaction was titanium oxide. The authors also analyzed the characteristics of the resulting polymer. The average particle size of titanium dioxide was determined using a microanalyzer HoribaLB-550, it was $45 \mathrm{~nm}$. The effect of reaction time and hardener content on the properties of polydimethylsiloxane was studied. The optimal conditions for the synthesis were established. The optical properties of the polymer were studied using UV-VIS spectroscopy on the Unico-2800 spectrometer. It was found that the use of orthotitanic acid ether leads to a strong absorbing effect in the shortwave region of the spectrum, starting from $400 \mathrm{~nm}$. Depending on the content of orthotitanic acid isopropyl ether and curing time, Shore A hardness was determined. The adhesive properties of the composition on a glass and steel substrate were studied. Tear strength reached 2.2 MPa.
\end{abstract}

\section{References}

[1] N.B. Kondrashova, V.A. Valtsifer, V.N. Strelnikov, V.Ya. Mitrofanov, and S.A. Uporov. Magnetic characteristics of mesoporous materials $0.1 \mathrm{NiO}-1 \mathrm{SiO}_{2}$ as influenced upon by introduction of trialkoxysilane additives during synthesis. Butlerov Communications. 2015. Vol.41. No.1. P.159-162. DOI: $10.37952 / R O I-j b c-01 / 15-41-1-159$

[2] V.Yu. Chukhlanov, N.N. Smirnova, N.V. Chukhlanova, and E.E. Mastalygina. Syntactic foams based on hollow ceramic microspheres and binder of oligomethylsilsesquioxane. Butlerov Communications. 2018. Vol.56. No.10. P.107-111. DOI: 10.37952/ROI-jbc-01/18-56-10-107

[3] A.A. Kapustina, V.V. Libanov, A.A. Rumina, N.P. Shapkin, and T.I. Akimova. Study of the interaction of tin(II and IV) and titanium(IV) oxides with polyphenylsiloxane by mechanochemical activation. Butlerov Communications. 2018. Vol.56. No.12. P.118-125. DOI: 10.37952/ROI-jbc-01/18-56-12-118

[4] N.N. Smirnova. Interpolyelectrolyte complexation of sulfonate-containing aromatic polyamides in aqueous solutions. Butlerov Communications. 2018. Vol.53. No.2. P.87-93. DOI: 10.37952/ROI-jbc01/18-53-2-87

[5] A.V. Varaksin, V.L. Lisin, V.A. Kostilev, L.I. Leontiev, E.V. Ignatieva, A.B. Shubin, and S.A. Petrova. Application of composite agglomerates based on $\mathrm{WC}$ and $\mathrm{TiC}$ produced by electrochemical technology for preparation of antiwear coatings by direct laser cladding. Butlerov Communications. 2016. Vol.48. No.10. P.14-22. DOI: 10.37952/ROI-jbc-01/16-48-10-14

[6] L.M. Hananashvili, K.A. Andrianov. Technology of organoelement monomers and polymers. Moscow: Chemistry. 1983. 400p. (russian)

[7] E.G. Makarov. Math Mathcad 15. Training course. Moscow: Peter. 2011. 400p. ISBN 978-5-459-00357-4. 
THE PROCESS OF OLIGODIMETHYLSILOXANE WITH TERMINAL HYDROXYL GROUPS AND ISOPROPYL... 36-41

[8] D.V. Kiryanov. Mathcad 15 / Mathcad Prime 1.0. Moscow: BHV-Petersburg. 2012. 432p. ISBN 978-59775-0746-2.

[9] N.N. Smirnova, I.A. Nebukina. Kinetics of sorption and desorption of lisozyme of ultrafiltration membranes based on aromatic polyamides. Sorption and chromatographic processes. 2015. Vol.15. No.1. P.51-59. (russian)

[10] C.-T. Lo, F.C. Laabs, B. Narasimhan. Interfacial adhesion mechanisms in incompatible semicrystalline polymer systems J. Polym. Sci. part B. 2004. Vol.42. No.14. P.2667-2679. 